\title{
0 IMIGRANTE E SEUS IRMÃOS: AS PESQUISAS EMPÍRICAS DE FLORESTAN FERNANDES E GINO GERMANI
}

Antonio Brasil Jr. *

Sob esse aspecto, o imigrante poderia ser comparado ao judeu das descrições e interpretações de Sombart (FERnANDES, 2006, p. 156)

Um enigma: o imigrante (GERMANI, 2006, p. 237).

Em fins dos anos 1950, a temática do desenvolvimento econômico e social começa a se tornar dominante na sociologia produzida na América Latina. Um evento marcante, neste sentido, foi o seminário internacional "Resistências à mudança: fatores que impedem ou dificultam o desenvolvimento”, organizado em 1959 por Luiz A. Costa Pinto no recém-criado Centro Latino-Americano de Pesquisas em Ciências Sociais (Clapcs), que reuniu sociólogos de toda a região, além de convidados europeus e norte-americanos. No entanto, esta convergência temática não era propriamente uma especificidade da produção sociológica da região. Também nos Estados Unidos, e no mesmo período, a "sociologia da modernização" reorientou de maneira significativa as análises aí desenvolvidas no tocante aos ritmos e sentidos da mudança social. Estas formulações ganharam

\footnotetext{
* Este artigo é parte de uma pesquisa mais ampla, em andamento, sobre a "aclimatação" da "sociologia da modernização" na América Latina. Gostaria de agradecer a André Botelho, orientador da tese, Alejandro Blanco e Simone Meucci pela leitura e crítica de diferentes versões deste texto. É desnecessário dizer que os argumentos aqui desenvolvidos são de minha inteira responsabilidade.
} 
intensa circulação na América Latina, tanto em virtude do papel de liderança ocupado pela sociologia norte-americana no pós-guerra, quanto por sua difusão através de agências internacionais como a Unesco. As formulações de autores como Talcott Parsons, Everett Hagen, Bert Hoselitz, Seymour Lipset e Daniel Lerner, dentre outros, foram lidas, traduzidas e incorporadas ao repertório cognitivo da produção sociológica latino-americana.

Em que pese o impacto da "sociologia da modernização" na América Latina, podemos dizer que aqui se formou, ainda assim, um espaço próprio de acumulação intelectual. Ao longo do processo de "aclimatação" daquelas formulações, gestou-se algo diferente e que foi capaz de interpelá-las criticamente, colocando a própria questão do desenvolvimento noutro patamar teórico. Neste artigo, propomos uma análise da produção de dois sociólogos que foram decisivos neste aspecto: Florestan Fernandes e Gino

176 Germani, protagonistas da renovação da sociologia nas universidades de São Paulo e de Buenos Aires, respectivamente $^{1}$. Ainda que as possibilidades de comparação entre os dois autores sejam variadas e já assinaladas noutros trabalhos (Miceli, 2007; Blanco e Jackson, 2008), permanece pouco explorado o ângulo adotado aqui, a saber, o de um exercício comparativo entre as pesquisas empíricas dirigidas por Fernandes e Germani nos anos 1950-60, sob a hipótese de que estas foram fundamentais para as inovações teóricas que eles apresentaram posteriormente em livros como A revolução burguesa no Brasil (1975) e La sociología de la modernización (1969).

\footnotetext{
${ }^{1}$ Para uma análise da renovação da linguagem sociológica em São Paulo (centrada em Florestan Fernandes) e suas conexões com o processo de metropolização cultural da cidade, ver Arruda (2001). Um estudo bastante abrangente sobre a reorientação empreendida por Gino Germani na sociologia argentina pode ser encontrado no trabalho de Alejandro Blanco (2006).
} 
As pesquisas que reconstruiremos aqui gravitaram em torno de dois projetos coletivos, situados num momento de grande fermentação universitária e de iniciativas internacionais de suporte institucional e financeiro à investigação empírica na América Latina. Por um lado, o projeto "O preconceito racial em São Paulo” (1951), redigido por Florestan Fernandes e assinado (com modificações) por este e Roger Bastide, que se configurou como uma das várias pesquisas patrocinadas pela Unesco sobre a questão racial no Brasil (Maio, 1997). Por outro, o projeto "El impacto de la inmigración masiva sobre la sociedad y la cultura argentinas" (1960) (posteriormente renomeado como "El impacto de la inmigración masiva en el Río de la Plata”), fruto de uma parceria entre Gino Germani e a cátedra de História Social, dirigida por José Luis Romero ${ }^{2}$, projeto que contou com o aporte financeiro da Fundação Rockefeller.

A fim de construir a comparabilidade entre os dois projetos e a produção que deles resultou, escolhemos um elemento que permitisse conectar, de maneira interna, a problemática desenvolvida pelos autores. Em A integração do negro na sociedade de classes (1964), de Fernandes, e numa série de textos de Germani, alguns deles reunidos em Política y sociedad en una época de transición (1962), os dois autores chamaram a atenção para o imigrante de ultramar como um dos principais (senão o principal) portador das mudanças sociais em curso, cuja integração bem-sucedida nos setores mais dinâmicos da ordem capitalista emergente se daria concomitantemente à integração limitada ou precária de outros grupos sociais. No entanto, os autores

\footnotetext{
${ }^{2}$ Os principais resultados deste projeto foram publicados em Argentina: sociedad de masas (1965) (organizado por G. Germani, J. Graciarena e T. Di Tella) e Los fragmentos del poder (1969) (compilado por T. Di Tella e T. Halperín Donghi), nos quais se encontra uma série de artigos coletivos reunindo sociólogos (vários deles alunos ou ex-alunos de Germani) e historiadores na análise do impacto da imigração estrangeira no sistema de estratificação, na urbanização e na industrialização, no sistema político etc.
} 
também apontaram para o aspecto problemático da ação do imigrante, porquanto o seu caráter inovador na esfera econômica se articularia a um baixo ou escasso impacto na democratização da sociedade. Estas questões, conforme sugerido no final deste artigo, permitiram que Fernandes e Germani ganhassem um ângulo privilegiado para observar a não linearidade da mudança social, ponto-chave das proposições teóricas desenvolvidas por eles em fins da década de 1960 .

No caso de Fernandes, a análise da integração relativamente bem-sucedida do imigrante em São Paulo se apresenta à contraluz da difícil e lenta integração do grupo negro, prisma sob o qual analisará as hesitações e dubiedades da sociedade de classes em formação ${ }^{3}$. Ainda, será sobretudo através de uma pesquisa de campo com os grupos negros da metrópole paulistana, usando técnicas como a entrevista e a observação direta, que a equipe responsável pela coleta de 178 dados fornecerá o grosso do material empírico levantado. Vale ressaltar que a questão da imigração propriamente dita também se fazia presente no horizonte intelectual de Fernandes, pois seu projeto original de doutorado tinha como objeto a "aculturação religiosa" de um grupo de imigrantes sírio-libaneses em São Paulo. Esta pesquisa, apesar de inconclusa, se estendeu por toda a década de $1950^{4}$, e certa-

\footnotetext{
${ }^{3}$ Os seus orientandos, Renato Jardim Moreira, Fernando Henrique Cardoso e Octavio Ianni, estenderiam a pesquisa sobre a integração do negro para outros estados do sul do Brasil, realizando pesquisas em Florianópolis, Curitiba, Porto Alegre e Pelotas. Ver o texto escrito pelos três e apresentado na II Reunião Brasileira de Antropologia, "O estudo sociológico das relações entre negros e brancos no Brasil Meridional" (1957).

${ }^{4}$ Desta pesquisa sobre a "aculturação religiosa" dos sírio-libaneses em São Paulo temos poucas referências publicadas, para além de sua menção em entrevistas por parte do autor. Um delas está na resenha escrita por Fernandes (1949) do livro A aculturação dos alemães no Brasil, de Emilio Willems, na qual diz trabalhar "no mesmo campo, em São Paulo - estudando a aculturação religiosa dos sírio-libaneses" (p. 217). A este respeito, o autor publicou apenas dois artigos: "A aculturação dos sírios e libaneses em São Paulo" (1956) e "O Brasil e o mundo árabe" (1967).
} 
mente não deixou de afetar a fatura de $A$ integração do negro na sociedade de classes, tese de cátedra defendida em 1964.

Para Germani, por sua vez, a análise do imigrante de ultramar (e da imigração) é o foco da investigação. No entanto, simultaneamente ao projeto "El impacto de la inmigración masiva...", ele também se engajou noutra iniciativa coletiva de pesquisa, desta vez em parceria com os Institutos de Medicina e de Nutrição da Universidade de Buenos Aires (UBA), destinada à análise das condições de vida num bairro operário de Avellaneda, a "Isla Maciel". Este bairro, conformado sobretudo por migrantes do interior argentino, sugeria um quadro bastante distinto em relação à integração bem-sucedida dos imigrantes de ultramar, já que os primeiros ainda se encontravam pouco integrados social e culturalmente ao meio urbano. No plano metodológico, os principais esforços da equipe liderada por Germani se concentraram na confecção de uma amostra de mais de 2 mil famílias que fosse representativa da Grande Buenos Aires, o que possibilitaria a utilização de técnicas estatísticas de inferência e generalização.

Cumpre lembrar, assim, que este exercício de aproximação não pretende apagar as diferenças significativas que existem entre as formulações de Fernandes e Germani. Isto porque a própria maneira pela qual se organizou o debate a respeito da "questão nacional" foi diferente no Brasil e na Argentina nos anos 1950: aqui, o debate se polarizou em torno da "questão racial" e do padrão, democrático ou não, de relação entre brancos e negros ${ }^{5}$; na Argentina, ele

\footnotetext{
${ }^{5}$ Em sua pesquisa de doutorado, Marcos C. Maio reconstrói o amplo painel dos estudos relacionados à "questão racial" patrocinados pela Unesco no Brasil, envolvendo, para além de Fernandes e Bastide, Oracy Nogueira, Thales de Azevedo, René Ribeiro e Luiz Costa Pinto (e em contraponto também Guerreiro Ramos). Embora ela já tivesse sido debatida no "ensaísmo" dos anos 1920-30, a "questão racial" ganha novos contornos nos anos 1950, sendo marcada pelo tema do "desenvolvimento". Nos termos de Maio: "Não obstante a pesquisa da Unesco remeter de imediato a um tema específico, ou seja, as relações raciais, ela serviu de "pretex-
} 
se articulou em torno do "peronismo" e sobre os grupos sociais que lhe davam sustentação política (especialmente os recém-migrados do interior argentino $)^{6}$. Como veremos mais adiante, seja por suas tomadas de posição a respeito da "questão nacional" em seus respectivos países, seja pelas diferentes formas de recortar a realidade e proceder à investigação empírica, os esforços de Fernandes e Germani também se distanciam em vários aspectos.

Com fins de organizar a comparação, dividiremos o artigo em três partes: (a) no que se refere às maneiras pelas quais Fernandes e Germani incorporaram a dimensão histórica como uma componente fundamental da explicação sociológica; (b) como eles analisaram os diferentes graus de integração social dos grupos sociais à cidade de São Paulo e à Grande Buenos Aires (que são os seus recortes empíricos); e, por fim, (c) em que sentido o processo analisado e os atores sociais nele presentes lograram ou não democrati180 zar as sociedades brasileira e argentina, respectivamente.

\section{A dimensão histórica}

Nos dois livros de Florestan Fernandes que se originaram diretamente das pesquisas sobre as relações raciais em São Paulo, Brancos e negros em São Paulo (em parceria com Roger Bastide) e A integração do negro na sociedade de classes, não só o recurso ao passado ocupa um peso central na explicação ${ }^{7}$, como a sua reconstrução tem alcances distin-

\footnotetext{
to' para diversas análises acerca da transição do arcaico para o moderno" (Maio, 1997, p. 314).

6 "Há meio século o peronismo vem sendo objeto de polêmica: um conjunto de fatos, motivos, metáforas e identidades tratados como legítimo objeto de discordância e tomada de posição [...]. Por muito tempo, interpretar o peronismo foi um tema tão central nas lutas intelectuais argentinas que, para ser ouvido, qualquer indivíduo interessado em falar sobre a realidade social e cultural do país tinha de participar do debate sobre as origens e a natureza do peronismo" (Neiburg, 1997, p. 15).

${ }^{7} \mathrm{Na}$ introdução a $O$ negro no mundo dos brancos, esta preocupação com a dimensão histórica é reafirmada: "não tentamos explicar o presente pelo passado, o que
} 
tos em cada um, como veremos mais à frente. No primeiro, o autor especifica o papel econômico e social desempenhado pelas populações negras desde o começo da colonização do planalto paulista, ressaltando de que modo a escravidão, no período posterior à decadência da mineração, agiu como um "fator social construtivo" (Fernandes, 2008a, p. 42), ou seja, criou as bases para o desenvolvimento da grande lavoura de exportação no século XIX - evitando, assim, o retorno a uma simples economia de subsistência. Deixando de ser um elemento marginal à economia da região, diz Fernandes, "durante quase um século" os negros foram "os únicos agentes do trabalho escravo e os principais artífices da produção agrícola”. Nesta chave de leitura, que se apropria de algumas teses de Caio Prado Jr., mas também mobiliza Roberto Simonsen, Sérgio Buarque de Holanda, dentre outros, interessa ao autor situar uma particularidade histórica de São Paulo: o período no qual as plantations de café atingem o seu maior ponto de rendimento "coincide com o período em que se inicia e se processa o colapso do sistema de trabalho escravo no Brasil" (Fernandes, 2008a, p. 58).

Neste sentido, o quadro histórico apresentado pelo autor chama a atenção para os dois desdobramentos principais deste "colapso": o primeiro, o caráter conservador da Abolição, que concedeu ao negro apenas "uma liberdade teórica, sem qualquer garantia de segurança econômica ou assistência compulsória" (Fernandes, 2008a, p. 65); o segundo, a entrada massiva de imigrantes europeus a fim de "corrigir as limitações do mercado interno de trabalho", drenando "sem cessar milhares de indivíduos

seria irreal numa sociedade de classes em formação e em rápida expansão. Porém, combinamos a análise sincrônica à análise diacrônica, num modelo dialético de fusão da perspectiva histórica com a perspectiva estrutural-funcional" (Fernandes, 2007, p. 26). 
de diversas regiões da Europa para as lavouras paulistas" (Fernandes, 2008a, p. 58). Desta combinação resultou que, apesar do fim da escravidão e da maior diferenciação da economia paulista, incluindo aí o crescimento acelerado da cidade de São Paulo, a abertura de postos de trabalho no mundo urbano não modificou "a posição do negro no sistema de trabalho", porque

à medida que se processava a desintegração do acanhado artesanato do período colonial, as ocupações independentes ou rendosas caíam continuamente nas mãos dos imigrantes europeus (Fernandes, 2008a, p. 59).

É justamente sobre este "drama histórico" que se concentra a maior parte da reconstrução histórica apresentada em $A$ integração do negro na sociedade de classes.

Neste livro, Fernandes faz uso de uma série de dados 182 referentes ao grande impacto demográfico, econômico e sociocultural representado pela entrada de um elevado contingente de imigrantes na capital paulistana. Ainda que as cifras não cheguem aos mesmos patamares da capital argentina, são bastante consideráveis: se no início do século XIX "o elemento negro e mulato, escravo ou livre, constituía aproximadamente $54 \%$ da população local” (Fernandes, 2008b, p. 36), já em 1886 os "imigrantes radicados na cidade excediam em 1870 indivíduos (ou seja, em 3,9\%) a população considerada no censo como 'preta' e "parda'" (Fernandes, 2008b, p. 37). Em termos percentuais, já atingiam $25 \%$ do total. Contudo, este impacto acarretado pela imigração de ultramar produziu, de acordo com Fernandes, impactos desiguais ao longo da estrutura social. No censo da capital de 1893, por exemplo, nota-se uma conexão forte entre a população imigrada e as profissões mais dinâmicas da nova ordem capitalista: constituíam $79 \%$ dos operários, 85,5\% dos artesãos, 81\% dos empregos relacio- 
nados aos transportes e 71,6\% dos empregos comerciais. No conjunto da população ativa, isto é, "nos setores que operavam como fulcros da rápida expansão urbana e da industrialização, a participação dos trabalhadores estrangeiros era da ordem de 82,5\%" (Fernandes, 2008b, p. 43). Nos termos do autor:

O fato de a urbanização e a industrialização se darem, em grande parte, como consequência da imigração concedia ao imigrante uma posição altamente vantajosa em relação ao elemento nacional e, em segundo lugar, quase anulava as possibilidades de competição do negro e do mulato, automaticamente deslocados para os setores menos favorecidos do conglomerado nacional (Fernandes, 2008b, p. 163).

Que os imigrantes tenham garantido para si os melhores postos de trabalho que se abriam à competição requer, para Fernandes, uma explicação sociológica. Para ele, os ex-escravos, ao contrário dos imigrantes, não conseguiram se ajustar às novas exigências do mercado de trabalho livre por conta de sua socialização inadequada a uma situação de classes $^{8}$ : "tornava-se difícil ou impossível, para o negro e o mulato, dissociar o contrato de trabalho de transações que envolviam, diretamente, a pessoa humana”. O imigrante, já socializado para um regime de trabalho livre, cumpria "à risca as obrigações decorrentes do contrato de trabalho, estimulado ainda mais pelo aguilhão de converter a sua força de trabalho em fonte de poupança". Ainda que repelisse "as

\footnotetext{
${ }^{8}$ A este respeito, ver a reconstrução feita por Bastos (1987) dos argumentos de Fernandes sobre a dinâmica de ressocialização. Neste texto, ela afirma que a "discussão sobre a socialização ultrapassa o nível explicativo meramente psicossocial. [...]. Mostrando que o negro é expulso não apenas da estrutura de trabalho tipicamente capitalista mas do sistema contratual como um todo, Florestan Fernandes aponta para os obstáculos à conquista dos direitos de cidadania” (pp. 144-145).
} 
condições de vida que não fossem 'decentes'”, o imigrante "percebia com clareza que somente vendia sua força de trabalho", enquanto que os negros "se ajustavam à relação contratual como se estivessem em jogo direitos substantivos sobre a própria pessoa" (2008b, p. 46). Como assinala o autor, os negros,

para manter a pessoa intangível, procuravam cumprir as obrigações contratuais segundo um arbítrio que, formalmente, prejudicava os interesses do contratante, por causa das incertezas e imprevistos que se introduziam na relação patrão-assalariado. A recusa de certas tarefas e serviços; a inconstância na frequência ao trabalho; o fascínio por ocupações real ou aparentemente nobilitantes; a tendência a alternar períodos de trabalho regular com fases mais ou menos longas de ócio; [...] essas e outras "deficiências" do negro e do mulato se entrosavam à complexa situação humana com que se defrontavam no regime de trabalho livre (Fernandes, 2008b, pp. 46-47).

No processo histórico reconstruído por Fernandes, portanto, a própria expansão da ordem capitalista se ajustou estruturalmente a uma profunda desigualdade entre as populações negras e imigradas. Preso ainda a móveis de ação "pré-capitalistas" - e neste ponto "a escravidão atingia o seu antigo agente no próprio âmago de sua capacidade de se ajustar à ordem social associada ao trabalho livre" -, a rapidez com a qual se processou a mudança social na cidade de São Paulo bloqueou aos negros e mulatos a "aquisição, pela experiência, da mentalidade e dos comportamentos requeridos pelo novo estilo de vida" (Fernandes, 2008b, p. 47).

No conjunto da produção de Germani dos anos 1950 e 1960, o texto que lhe serve de base para a reconstrução histórica da sociedade argentina é a publicação interna 
$\mathrm{n}^{\circ} 14$ do Instituto de Sociologia da UBA, La asimilación de los inmigrantes en la Argentina y el fenómeno del regreso en la inmigración reciente (1959) ${ }^{9}$. Neste informe, ao investigar como se deu a passagem, na Argentina, da "sociedade tradicional" à "sociedade moderna", Germani elege como ponto de inflexão histórica a atuação das elites liberais do período posterior ao governo de Juan Manuel de Rosas, cujo projeto político, denominado "Organização Nacional" ", tinha como objetivo "uma renovação da estrutura social do país, e, em particular, de seu elemento dinâmico principal, o elemento humano" (Germani, 1959, p. 7). E o elemento humano designado para este fim renovador seria o imigrante, especialmente o europeu, personagem que estaria associado diretamente à modernização da estrutura social argentina ${ }^{11}$.

Ao longo do texto, Germani procura especificar ao máximo o tipo de impacto acarretado pela imigração massiva de ultramar na estrutura social, especialmente na região da Grande Buenos Aires. Em relação ao seu aporte demográfico, embora já fosse um fenômeno considerável a partir da segunda metade do século XIX, a imigração só atingiria um caráter "massivo" entre os anos de 1880 e 1890, quando

\footnotetext{
${ }^{9}$ Este texto será republicado depois em diversas oportunidades, com acréscimos e modificações - aparecerá tanto em Política y sociedad en una época de transición (1962), como o oitavo capítulo, "La inmigración masiva y su papel en la modernización del país", quanto numa coletânea publicada nos Estados Unidos, com o nome de "Mass immigration and modernization in Argentina" (1970).

${ }^{10}$ Para uma análise deste projeto político, ver Halperín Donghi (2007).

${ }^{11}$ Apesar da crítica negativa de Germani ao "ensaísmo" argentino, incluindo a produção de José Luis Romero (a quem critica, neste texto, em nota de rodapé), esta forma de reconstrução do passado argentino tem algumas afinidades com a visada histórica proposta por este último. Porque também para Romero, com quem Germani dividia a responsabilidade do projeto "El impacto de la inmigración masiva...", seria possível distinguir uma Argentina "crioula", de corte marcadamente rural e tradicional, e uma Argentina "aluvial", cada vez mais urbana e europeizada - e também mais heterogênea -, sendo justamente o "aluvião imigratório" o principal responsável por esta transmutação histórica. Para uma comparação entre as formulações de Romero e Germani a respeito da "imigração massiva", ver Blanco (2009).
} 
as cifras anuais alcançam uma média de 64 mil pessoas. $\mathrm{O}$ processo se acelera nos anos posteriores, tendo atingido o seu ponto máximo

na primeira década do século [XX] (112 mil em média) e em particular nos anos imediatamente anteriores à Primeira Guerra Mundial, que registrou o ano recorde com um saldo na imigração de ultramar de mais de 200 mil pessoas (Germani, 1959, p. 7).

Entretanto, esta imigração sofre uma grave interrupção na década de 1930, quando se combinam diversos fatores, como a "depressão mundial, mudanças políticas na Argentina e nos países de emigração europeus (especialmente Itália)" (Germani, 1959, p. 7). Mesmo que as taxas voltem a se elevar depois da Segunda Guerra Mundial, já não recobrarão o aspecto massivo dos períodos 186 anteriores, o que será "compensado", segundo Germani, por um movimento de proporções análogas de deslocamento populacional das províncias do interior argentino e de outros países limítrofes (Bolívia, Paraguai e Chile) para a Grande Buenos Aires. Esta imigração estrangeira proveniente dos países vizinhos, que tomaria maior fôlego a partir de 1940 , seria

parte do processo de urbanização massiva mais recente, e os problemas que apresentam a assimilação destes migrantes são muito próximos aos de adaptação à vida urbana dos imigrantes internos de origem rural e semirrural (Germani, 1959, pp. 8-9).

No fundo, a leitura do passado recente e remoto da Argentina feita pelo autor será balizada por estas duas grandes "imigrações", a de ultramar e a interna (incluindo nesta última os estrangeiros de países limítrofes), e os impasses da 
modernização do país serão tratados a partir das especificidades de cada uma.

Em relação à imigração ultramarina, Germani chama a atenção para os seus efeitos desiguais em termos regionais e socioeconômicos. Por um lado, mesmo tendo contribuído para aumentar em doze vezes a população do país entre 1869 (1,7 milhão de habitantes) e 1959 (mais de 20 milhões de habitantes), seu impacto será muito mais significativo na região metropolitana de Buenos Aires, onde se multiplicou por 22 o número de habitantes no período 1869-1947, sendo que $50 \%$ deste crescimento se "deveu, entre 1869 e 1914, ao aumento do número de residentes estrangeiros". Noutras palavras, a Grande Buenos Aires "concentrou ao longo do período considerado entre 40 e 50\% da população estrangeira total” (Germani, 1959, p. 13), o que conferiu um tom essencialmente urbano ao fenômeno da imigração.

O fato de que a imigração de ultramar tenha se concentrado nas cidades requer, por parte de Germani, algumas explicações adicionais, especialmente porque, segundo afirma, "os imigrantes que chegaram em tão grandes massas pertenciam em sua grande maioria aos estratos mais pobres dos países de origem", e, até 1900, "pelo menos, se registrava uma preponderância de imigrantes camponeses" (Germani, 1959, p. 16). O principal fator apontado pelo autor foi a permanência do exclusivismo agrário, já que a propriedade fundiária não foi democratizada no processo de "Organização Nacional". Deste modo, dificultou-se "seriamente a realização de um dos propósitos principais da imigração massiva: a radicação de população europeia nas áreas rurais desertas ou quase desertas do país”. Diante destas condições, dada a inviabilidade dos imigrantes em se constituírem como proprietários rurais, "a maioria acabou por se fixar nas cidades” (1959, p. 19), aonde proporcionaram "uma abundante mão de obra urbana” (1959, p. 21). 
Embora não se detenha muito no que representou propriamente esta mudança abrupta para o conjunto da população imigrada, nem no modo pelo qual os mesmos conseguiram romper com o fardo da herança cultural rural de origem, Germani salienta que o processo imigratório é ele mesmo "inseparável do desenvolvimento econômico que se verificou de maneira contemporânea e em boa medida como resultado deste mesmo processo" $\left(1959\right.$, p. 17) ${ }^{12}$. Assim, num quadro histórico assemelhado ao reconstruído por Fernandes para a capital paulistana, também na Argentina, e especialmente na Grande Buenos Aires, os imigrantes de ultramar, e não os nativos, teriam se entrosado de maneira estreita às novas categorias ocupacionais modernas propiciadas pelo boom da economia primário-exportadora. Nesse processo de expansão, que "transformou a Argentina em um dos principais países exportadores quanto à sua produção agrícola", mas que também proporcionou a cons188 trução do "essencial do sistema de transporte ferroviário" e estimulou "o desenvolvimento de uma atividade industrial" (1959, p. 17), os imigrantes, assinala Germani, "desempenharam uma função de grande importância” (1959, p. 18). Nos seus termos:

A expansão do comércio exterior e interno e o aumento geral da riqueza, o aumento das atividades do Estado, a construção de obras públicas - particularmente a construção da rede ferroviária -, e, por fim, desde os últimos quinze ou vinte anos do século anterior, o surgimento e desenvolvimento da indústria, todas

\footnotetext{
${ }^{12} \mathrm{O}$ que, de fato, dá margem às interpretações que veem nos argumentos de Germani uma sobreposição do par "tradicional" /"moderno no par "argentino nativo" "imigrante de ultramar" (Halperín Donghi, 1975; Devoto, 1992). No entanto, Germani não concebe a "psicologia do imigrante" como uma variável independente, conectando-a sempre com os demais processos sociais. Para uma análise deste ponto de vista teórico, ver Germani (1973).
} 
estas atividades absorveram a massa de imigrantes que constituíam, como foi visto, a maioria da população das grandes cidades do país [...]. Aparentemente, no processo de transformação da sociedade argentina, que estava ocorrendo nesta época, os estrangeiros se situavam preferencialmente nos novos estratos que iam surgindo por causa do desenvolvimento econômico: empresários da indústria e do comércio, operários e empregados nestes dois ramos; quer dizer, predominavam sobretudo na classe média em expansão e no novo proletariado urbano-industrial, ambas categorias correspondentes às estruturas econômicas que substituíam as existentes na sociedade tradicional (Germani, 1959, p. 22).

Neste ponto, o autor pretende delimitar de maneira máxima a contribuição do imigrante na modernização da sociedade argentina: além de se concentrar geograficamente nos principais centros urbanos das zonas mais prósperas do país e na faixa demográfica de maior importância (os adultos do sexo masculino), também se fará mais presente como empresário capitalista, operário industrial e empregado no comércio urbano - justamente nos setores mais dinâmicos da nova ordem social em expansão. Daí Germani poder afirmar sua contribuição decisiva no aparecimento do "novo tipo de estratificação social que estava substituindo o tradicional" (1959, p. 24). Já os habitantes do mundo agrário argentino, mesmo quando imigrados posteriormente à Grande Buenos Aires, não conseguiriam igual êxito, permanecendo nas posições menos vantajosas que se abriam na ordem moderna emergente, como veremos abaixo.

\section{Os diferentes graus da integração social}

Vimos como para Fernandes e Germani a modernização acelerada de São Paulo e do Rio da Prata não logrou 
envolver igualmente todos os grupos sociais, repondo, em outro patamar, desigualdades seculares. Por meio de suas pesquisas empíricas, esta questão foi tratada através do prisma da integração social problemática experimentada pelo "meio negro", em São Paulo, e pelos "migrantes rurais", em Buenos Aires, em contraposição à bem-sucedida integração dos grupos de imigrantes de ultramar. Embora no vocabulário mais ou menos difundido pela "sociologia da modernização" houvesse a expectativa de que, uma vez iniciada, essa transformação tenderia a se expandir para a totalidade do sistema social, tanto Fernandes quanto Germani se depararam com processos que, de maneira estrutural, reforçavam a marginalidade de amplos setores da população, em vez de integrá-los na nova ordem em expansão ${ }^{13}$.

Antes de passarmos propriamente à análise dos resultados das pesquisas, vale a pena uma breve reflexão sobre 190 os procedimentos metodológicos e as técnicas de pesquisa adotados pelos autores e suas equipes. Embora estes "métodos" e "técnicas" fossem justamente aqueles que se difundiram com a internacionalização da sociologia como disciplina "científica", e que se impuseram com o padrão monográfico de trabalho sociológico, podemos dizer que,

\footnotetext{
${ }^{13}$ Neste sentido, Bastos (1996) nos ajuda a pensar - embora no texto em questão trate de Octavio Ianni - que, em mais de um sentido, as formulações de Fernandes ultrapassaram o marco funcionalista mais convencional do período, como a tese da "demora cultural". Isto porque existiriam, em sua análise, "elementos totalizadores da explicação", não sendo "por acaso que as diferentes esferas do social desenvolvem-se de forma descompassada" (p. 90). Duarcides Mariosa (2003), ao percorrer as pesquisas de Fernandes sobre os negros em São Paulo e sobre os Tupinambá, chama a atenção para a inovação teórica aí realizada, dado o uso criativo da noção de "integração" num registro em que convivem formas de exclusão e de hibridismo. Também no que se refere a Germani, Alejandro Blanco atenta para a lógica de apropriação bastante heterodoxa das formulações da sociologia da modernização (especialmente as de Talcott Parsons) por parte do autor de Política y sociedad en una época de transición. Além disto, posteriormente Germani (1973) tratou do tema da marginalização e de seu estatuto teórico na sociologia.
} 
ao operar com tais métodos, sua própria "aplicação" foi altamente tingida, por assim dizer, pela "cor local”, isto é, pela problemática que estruturava o debate intelectual em seus respectivos países - a "questão racial", no caso de Fernandes, e a "questão peronista", no caso de Germani. Assim, longe de serem apenas "aplicações" de técnicas inteligíveis em si mesmas, é possível localizar já no modus operandi a forma particular com a qual os autores lidavam com os fenômenos que pretendiam analisar.

Em A integração do negro na sociedade de classes, comparece uma série de dados de natureza quantitativa, ainda que estes não conformem a maior parte do material empírico reunido. O grosso do material é fruto da "pesquisa de campo realizada em 1951" complementada, como esclarece Fernandes, "por informações levantadas anteriormente, entre 1940 e 1949, seja por alunos do professor Roger Bastide ou por este mesmo, seja pelo próprio autor e por seus alunos" (Fernandes, 2008c, p. 191). Talvez até mesmo pelo tipo de técnicas utilizadas - "histórias de vida", entrevistas, questionários e observações diretas ${ }^{14}$-, a relação de Fernandes e de sua equipe de pesquisa com os diversos segmentos da população negra de São Paulo foi bastante estreita, incluindo aí parte considerável de seus intelectuais. Basta lembrarmos que uma das referências bibliográficas principais do livro é a monografia escrita a quatro mãos por Renato Jardim Moreira, orientando de Fernandes, e José Correia Leite, importante líder do movimento negro em São Paulo ${ }^{15}$.

\footnotetext{
${ }^{14}$ Para uma reflexão sobre o uso da "história de vida" na produção de Florestan Fernandes, ver Martins (1998).

${ }^{15}$ Trata-se da monografia "Movimentos sociais no meio negro", infelizmente não localizada. Ver, para maiores informações neste sentido, Moreira (1953). Em sua pesquisa de doutorado, ainda em curso, Mário Augusto Medeiros da Silva (2010) vem mostrando que o contato travado entre Florestan Fernandes e seus orientandos e os intelectuais nucleados na Associação Cultural do Negro em São Paulo era intenso, sendo possível captar nexos de sentido entre as produções dos primeiros e dos últimos.
} 
Esta relação foi decisiva não só na maneira pela qual foi levada a cabo a pesquisa, mas também porque, em mais de um sentido, a própria armação do argumento desenvolvido ao longo livro é uma espécie de diálogo crítico, embora mediado pelas categorias sociológicas, com as representações coletivas desenvolvidas no interior da coletividade negra. Exemplificando: na discussão sobre a existência ou não do "preconceito de cor", questão que polarizou a bibliografia referida sobre o tema, Fernandes trabalha o problema num duplo registro: num plano, o "preconceito de cor" funciona como uma noção sociológica, mobilizada pelo autor ao lado de outras; noutro, como uma "categoria histórico-social", forjada no seio das próprias organizações da população negra e difundida por meio de sua imprensa periódica. Neste sentido, diz Fernandes que a noção de "preconceito de cor" atuava também como "uma categoria inclusiva de pensamento", isto

192 é, como uma categoria que permitia aos negros "designar, estrutural, emocional e cognitivamente, todos os aspectos envolvidos pelo padrão assimétrico e tradicionalista de relação racial" (Fernandes, 2008c, p. 44). Noutras palavras, a "contraideologia" racial elaborada pelos movimentos negros é ela mesma incorporada, ainda que apontando os seus limites e recalibrada pela explicação sociológica, nas formulações de Fernandes ${ }^{16}$.

No caso da pesquisa liderada por Germani na Grande Buenos Aires, a escolha do survey como instrumento

\footnotetext{
${ }^{16}$ Fernandes reconhece que, do material levantado na pesquisa, apenas um quarto dele foi coligido junto às populações brancas. Isto se daria, segundo o autor, porque "o eidos, o logos e o ethos da percepção e da explicação da realidade racial ambiente, no que diz respeito ao 'branco', ainda se definem através de influências diretas ou indiretas do horizonte cultural tradicionalista" (Fernandes, 2008c, p. 459). Neste sentido, no que toca à questão das relações raciais em São Paulo, os negros teriam desenvolvido um aparato cognitivo muito mais complexo que os brancos, pois o "preconceito de cor" forçaria o negro "a romper a obnubilação condicionada pelo horizonte cultural com as imagens correntes da nossa realidade social" (Fernandes, 2008c, p. 460).
} 
metodológico já de saída se explicaria pelas possibilidades de estabelecer comparações precisas com outras trajetórias nacionais. Desenhado no âmbito de uma pesquisa mais ampla patrocinada pelo Clapcs sobre "Estratificação e mobilidade social em quatro capitais latino-americanas" (Costa Pinto, 1959), embora também servisse para fornecer os dados para a pesquisa sobre a "Assimilação de imigrantes”, à primeira vista a construção do survey não seria afetada pelas particularidades da experiência sócio-histórica argentina. Contudo, num ponto central a própria construção da amostra utilizada retraduziria esta experiência: a fim de distinguir os diferentes estratos sociais, definidos a partir de um "índice de Nível Econômico Social”, Germani se ampara nos dados eleitorais de 1958, com a justificativa de que, "com base em outros estudos", existiria "uma correlação de 0.90 (correlação ecológica) entre a porcentagem de voto no peronismo [...] e o percentual de operários" (Germani, 1962a, p. 17). Isto é: quanto maior a concentração de votos peronistas, maior a quantidade de grupos pertencentes às classes populares (e vice-versa). Neste sentido, a construção da escala de estratificação social usada na pesquisa é ela mesma tributária de uma leitura das bases sociais do peronismo, questão que encerraria considerável polêmica nas décadas seguintes ${ }^{17}$. No que se refere à pesquisa realizada na "Isla Maciel", também aí o "peronismo" se impôs nos procedimentos de pesquisa: região de considerável militância peronista, Germani só pôde realizar as entrevistas com as famílias do

\footnotetext{
${ }^{17}$ A discussão sobre as bases sociais do peronismo ganhou grande fortuna no debate sociológico e político mais amplo na Argentina. Estudios sobre los orígenes del peronismo, de Miguel Murmis e Juan Carlos Portantiero, publicado em 1971 é em certa medida um livro pioneiro na revisão da tese de Germani, que se amparava na associação entre o "peronismo" e os grupos migrantes do interior argentino, como mais adiante será visto. Um bom balanço bibliográfico desta questão se encontra em De Ípola (1989).
} 
bairro após um longo período de contato, pois, como ele mesmo admite, era muito difícil assegurar uma relação favorável com o grupo estudado em virtude das "circunstâncias imperantes" que "dificultavam ou até impediam a comunicação entre diferentes setores da população, ainda comovida pelos acontecimentos de setembro de 1955" (Germani, 1962b, p. 210).

Vejamos agora, pois, alguns resultados das pesquisas empíricas de Fernandes e Germani. Se, como vimos mais acima, é possível aproximar, tal como aparece nos argumentos dos autores, a ação do imigrante de ultramar nos dois contextos em virtude da posição que eles ocuparam no processo de modernização, parece mais arbitrário, no entanto, fazer algo parecido em relação às populações negras de São Paulo e os migrantes internos de origem rural na Grande Buenos Aires. Podemos dizer, no entanto, que o próprio Fernandes nos autoriza a fazer esta aproximação. Em docu194 mento interno do Centro Brasileiro de Pesquisas Educacionais (CBPE), que patrocinou, em parte, a preparação de $A$ integração do negro na sociedade de classes, o autor assinala que o conhecimento da situação do negro em São Paulo permite dar conta também das dificuldades de ajustamento das populações "rústicas" como um todo à capital paulistana. Em seus termos:

Por seus caracteres sociais e culturais, essa camada é comparável ou assimilável a outras populações rústicas brasileiras, que não estão socializadas para a vida social urbana. [...] Por isso, o estudo do que se passou com esse segmento da população paulistana permite conhecer e esclarecer processos que ocorreram e tendem a ocorrer, ainda hoje, quando indivíduos ou grupos de populações rústicas brasileiras concorrem por ocupações e classificação social na sociedade paulistana. A sociedade de classes 
em desenvolvimento necessita desses indivíduos e grupos, que passam, de maneira dramática, da vida social rústica para a vida social urbana (Fernandes, 1959, pp. 1-2).

Feito este esclarecimento inicial, voltemos aos argumentos de A integração do negro na sociedade de classes. Neste livro, pelos motivos históricos já discutidos acima, a emergência de uma ordem capitalista em São Paulo teria tido consequências muito desiguais na organização da vida das populações negras e imigradas: para as primeiras, expelidas de seu núcleo dinâmico, significou a agravamento das condições anômicas herdadas da escravidão, prendendo-as a um tradicionalismo "rústico"; para as segundas, inseridas nas posições estratégicas da nova ordem, significou a sincronização entre os modos de agir e pensar às "exigências" da sociedade de classes, não obstante o recurso a elementos "tradicionais" (reforço da solidariedade familiar em torno da autoridade paterna, por exemplo) fosse bastante frequente. Dada a participação marginal do negro na "civilização urbana” durante as primeiras décadas do século XX atuaria o seguinte "círculo vicioso":

Essa exclusão [...] acentuou e agravou o isolamento econômico, social e cultural do negro, aumentando a sua dependência e, provavelmente, o seu apego a uma herança sociocultural imprópria e desvantajosa. Os efeitos acumulativos dessa interação de fatores se encadearam de tal modo que fizeram do elemento negro o único agrupamento humano da cidade em que não se revela um mínimo de sincronização entre as tendências e os produtos da "urbanização", da "mobilidade social" e da "secularização da cultura" (Fernandes, 2008b, p. 87). 
A fim de investigar os efeitos "sociopáticos" da desorganização social no "meio negro", Fernandes confere grande importância à questão da constituição familiar, não só por sua centralidade para as instâncias de socialização como por sua recorrência nas "histórias de vida" coligidas pela pesquisa. No seio da "população de cor", diz o autor que esta instituição, "tal como ela se manifesta em São Paulo durante as três primeiras décadas deste século XX, poderia ser definida como uma família incompleta". E agrega: "parece fora de dúvida que o arranjo mais frequente consistia no par, constituído pela mãe solteira ou sua substituta eventual, quase sempre a avó, e seu filho ou filhos” (Fernandes, 2008b, p. 240). Esta deficiência institucional da família negra, também presente durante o período da escravidão, traria complicações adicionais na nova ordem em expansão, sobretudo na competição com os padrões impostos pelos imigrantes. Em virtude da mudança acele196 rada ocorrida na cidade de São Paulo,

essa limitação se apresentava, sem exagero, como verdadeiramente catastrófica. Numa sociedade de classes em formação, a família vinha a ser o principal e, por vezes, o único ponto de apoio grupal com que contavam os indivíduos.

Ou dito de outra maneira:

Sem um mínimo de cooperação e de solidariedade domésticas, ninguém podia vencer naquela "selva selvagem"; a "competição individualista", irrefreada ou não, requeria um complexo substrato institucional, de que a família integrada constituía o patamar. Os exemplos dos imigrantes são conclusivos, pois entre eles a família sempre servia, direta ou indiretamente, de alicerce à rápida ascensão econômica, social e política (Fernandes, 2008b, p. 238). 
No entanto, nem a constituição do "meio negro" em São Paulo era homogênea, nem persistiriam indefinidamente as tendências de desorganização social - pelo menos uma parte desse "meio negro" paulistano conseguiu lentamente se classificar na sociedade de classes. Fernandes expõe em diversas passagens do livro, através do material coletado, algumas maneiras pelas quais o "meio negro" pôde, "com grande atraso e enormes deficiências", "de modo lento e descontínuo", absorver as instituições sociais "que se tornaram básicas para a conformação do horizonte cultural, a organização da vida e a integração no regime de classes" (Fernandes, 2008b, p. 284). Entre elas, está o uso da inteligência no aproveitamento criador das experiências do imigrante, especialmente do italiano:

O negro e o mulato descobriram no convívio ou na observação da "vida do italiano" a importância da família.

[...] O negro ou o mulato "ordeiros", propensos a "respeitar" a família, nos porões ou nos cortiços podiam ser estimulados nessa direção. A presença de brancos “estrangeiros”, com vida familiar estável e organizada, estabelecia um ponto de referência que dava um novo sentido àquela propensão (Fernandes, 2008b, p. 243).

A esta modernização e maior integração social do negro, isto é, sua ressocialização para a "civilização urbana”, seguiram-se, para Fernandes, dois processos: um deles foi, como era de se esperar, a sua maior capacidade competitiva em relação aos demais grupos sociais, jogando-o nos caminhos da ascensão social facilitada pela interrupção das correntes imigratórias e pelo crescimento industrial no período da Segunda Guerra Mundial; o outro foi a formação de movimentos sociais. Contudo, o negro não conseguiria repetir o feito do imigrante, assinala o autor, tanto pelo grau limitado de sua inserção nas posições 
estratégicas da ordem industrial em formação, quanto pela maior complicação ulterior da sociedade de classes. Diz Fernandes que, embora os negros já pudessem "reproduzir os procedimentos dos velhos imigrantes", na "conjuntura atual as coisas são mais difíceis", pois "ninguém arredonda um pé de meia com base na poupança nem poderia se lançar com ele em empreendimentos compensadores" (2008c, p. 139). Combinando "os dados fornecidos pela situação ocupacional da 'população de cor' em 1940 com outros dados" recolhidos pela equipe "mediante questionários e entrevistas" (2008c, p. 151), Fernandes chega ao seguinte quadro:

No conjunto, portanto, a diferença decisiva, que se estabelece em relação ao passado recente, diz respeito à aquisição de uma fonte estável de ganho. Em outras palavras, o negro e o mulato conquistaram "meios de vida" que lhes proporcionam posições regulares (e por vezes permanentes) no seio do sistema de trabalho livre. No entanto, essas posições nem sempre asseguram classificação no sistema capitalista de relações de produção. Por isso, associam-se, variavelmente, com ocupações que proporcionam baixos níveis de remuneração e condicionam formas mais ou menos precárias da participação da estrutura de poder da sociedade inclusiva (2008c, pp. 158-159).

Nos resultados das pesquisas de Germani na Grande Buenos Aires, também transparece um quadro de integração desigual dos diferentes grupos sociais à metrópole portenha. Os dados extraídos a partir do survey realizado pela equipe de Germani foram publicados no texto "La movilidad social en la Argentina" (1963), apêndice $n^{\circ} 2$ da edição castelhana de Social mobility in industrial society (1959), de Reinhard Bendix e Seymour Lipset. Mesmo que os resultados apresentados nes- 
te informe sugiram amplas possibilidades ascensionais para o conjunto da população investigada - foram selecionadas, de maneira criteriosa, 2.262 famílias da Capital Federal e dos demais municípios da região metropolitana (Graciarena e Sautu, 1961) -, as chances de ascensão social se expressavam diferentemente de acordo com a origem geográfica, sendo muito maior para os imigrantes de ultramar e seus descendentes que para os migrantes do interior.

No agregado dos dados, quando se compara as diferentes posições socioeconômicas ocupadas ao longo de três gerações (pais, filhos e avôs paternos), Germani assinala que

o grau de fluidez do sistema de estratificação na zona de Buenos Aires [...] poderia ser sintetizado nas seguintes proporções: $29,7 \%$ de indivíduos permaneceram na posição de seus pais; $32,4 \%$ descendeu e $37,9 \%$ ascendeu, um ou mais níveis.

No que diz respeito à origem social dos entrevistados, os resultados mostraram que, "nos níveis médios (3, 4 e 5) em conjunto, pouco menos de $40 \%$ tem origem nos níveis baixos (1 e 2)"; em relação aos níveis altos (6 e 7), estes "revelam também um grau considerável de permeabilidade, posto que uma quinta parte é originária de famílias de nível operário e mais de 40\% de níveis médios" (Germani, 1963a, p. 339). Germani afirma que

esta interpenetração de pessoas de diferentes origens em distintos estratos sociais representa, provavelmente, um dos fatos de maior significado para se ter em conta ao analisar as consequências da mobilidade social (1963a, pp. 340-341).

Contudo, se as taxas de mobilidade social encontradas na Grande Buenos Aires são elevadas e, neste sentido, se aproximam (e até ultrapassam) os padrões encon- 
trados nos países "avançados", os sentidos deste processo teriam variado historicamente, especialmente quando se compara a época da imigração de ultramar com o período das grandes migrações internas. Por um lado, os setores médios teriam se expandido em ritmo acentuado nos dois momentos, numa "razão de 0,56\% anual entre 1869 e 1895 e entre 0,27 e $0,29 \%$ anual nas épocas posteriores até 1947, continuando provavelmente no mesmo ritmo na década dos anos 1950" (Germani, 1963a, p. 354). Por outro, a expansão constante das camadas médias teria afetado diferencialmente os imigrantes externos e internos: os primeiros conformaram a maior parte da classe média no período inicial de sua expansão; os segundos, posteriormente, ocupariam os níveis mais baixos, "empurrando" os nativos de Buenos Aires (em sua maioria filhos de estrangeiros) para as posições intermediárias que continuavam a se abrir. A hipótese aventada pelo autor para expli200 car esta divergência seria a natureza distinta dos setores médios "recentes", que exigiriam maior nível de escolaridade. Contrastando o período da migração interna com o da imigração externa, afirma:

As pessoas mais móveis (através da linha "manual”/“não manual”) não foram os estrangeiros, mas os argentinos nativos [...]. Além disto, já desde o começo do século as categorias de maior expansão foram os estratos médios “dependentes", isto é, empregados [de colarinho branco], categorias para as quais os estudos superiores e secundários representam um requisito essencial. Portanto, nesta época, a educação aumenta a sua importância em termos quantitativos, como canal de mobilidade ascendente (Germani, 1963a, p. 333).

De acordo com Germani, os resultados da pesquisa mostram que, ao se controlar o lugar de nascimento, a ascensão 
social de indivíduos de origem popular para níveis médios e altos se deu em muito maior número para os que nasceram em Buenos Aires que para os nascidos no interior - 47,8\% do total para os primeiros e $23,3 \%$ para os segundos. Se no período da imigração estrangeira massiva os "forasteiros" ascenderam em massa para as posições de classe média, no momento das grandes migrações internas foram justamente os "nativos" que aproveitaram as melhores oportunidades ascensionais. "É razoável supor”, diz Germani, "que um dos elementos diferenciais seja as facilidades educacionais que desfrutaram estes últimos" (1963a, p. 342). Apesar deste limite bastante nítido para a inserção dos argentinos nascidos no interior nas posições mais vantajosas do sistema de estratificação, a migração para a Grande Buenos Aires não deixou de significar, para os mesmos, um processo de considerável ascensão social.

Vale lembrar que, no que diz respeito a estes últimos, Germani também realizou uma pesquisa de campo na Isla Maciel, onde foram entrevistadas 210 famílias com distintos graus de integração à vida urbana. Mais especificamente, contrastou os habitantes mais antigos do bairro com os recém-migrados do interior, que viviam numa villa miseria [favela]. Um dos muitos índices usados por Germani na mensuração da adaptação de cada grupo ao meio urbano foi a qualificação do trabalho:

A maioria dos recém-imigrados se classificam na categoria de peões, operários sem nenhuma especialização, e apenas um quarto registra algum nível de capacitação. No grupo recém-imigrado, a proporção não especializada é aproximadamente a metade; no grupo nativo, ao redor de $15 \%$. Este último grupo inclui, além de operários especializados, certo número de artesãos que trabalham por conta própria e pessoal empregado subalterno. As mulheres do grupo recém- 
-chegado trabalham sobretudo no serviço doméstico e algumas poucas em indústrias (1962b, p. 224).

Esta divergência se refletiria de modo decisivo nas chances de ascensão social em cada grupo, e os resultados da pesquisa na Isla Maciel mostravam o mesmo padrão do survey:

os grupos revelam certas tendências ascensionais: maior proporção subindo que descendo. Mas enquanto que no grupo nativo a metade dos casos registrou uma ascensão (e $40 \%$ nos imigrados antigos), esta quantidade cai para $23 \%$ nos recentes (Germani, 1962b, p. 225).

A este acúmulo de desvantagens integrativas se juntariam também, nas famílias de imigração recente, os problemas típicos da desorganização social e da vida familiar, aliado às péssimas condições de vida na villa miseria. Nos termos 202 de Germani:

Os mecanismos de controle social - tanto no plano da família como no plano da comunidade local e da sociedade global - estão quase ausentes ou muito deteriorados na villa [...]. Por outro lado, tendem a se acumular nestas áreas não só os fatores de desmoralização devidos às dificuldades econômicas e às condições primitivas de habitação, mas também os que surgem da tendência a se concentrar nas mesmas os indivíduos já à margem do comportamento normal ou parcialmente desintegrados (1962b, pp. 234-235).

Assim, mesmo numa área em que quase a totalidade da população pertencia às camadas populares, também aí se manifestavam chances bastante desiguais de ascensão social quando comparados os nativos de Buenos Aires com os grupos rurais ou semirrurais recém-imigrados do inte- 
rior. Numa expressão semelhante à adotada por Fernandes sobre os anseios de classificação social dos negros em São Paulo, diz Germani que àqueles lhes "corresponderam os lugares menos favorecidos". Ainda que estejam "provavelmente repetindo", embora num "ambiente distinto e talvez mais difícil, a experiência de seus predecessores" (1962b, p. 224), isto é, os imigrantes estrangeiros, a escalada dos grupos migrantes internos se limitaria aos primeiros degraus da pirâmide social. Germani não esclarece, neste momento, se os grupos recém-imigrados passarão, com o tempo, a uma situação de integração mais ou menos completa às pautas modernas de comportamento, mas sugere que o caminho destes será mais complicado.

\section{Integração social, protagonismo político?}

Aparentemente, o quadro trazido pelas pesquisas de Fernandes e Germani sugere que os atores sociais problemáticos por excelência, no que se refere ao ajustamento à vida urbano-industrial, são, respectivamente, o negro e o migrante interno - embora Fernandes admita, como vimos mais acima, que as dificuldades do negro em São Paulo poderiam ser generalizadas também para o conjunto das populações "rústicas" imigradas à metrópole paulistana ${ }^{18}$. Contudo, o relativo êxito do imigrante de ultramar, que praticamente monopolizou as posições mais dinâmicas da ordem capitalista em expansão nos dois contextos, tampouco o isentaria de problemas. Cada qual a seu modo, Fer-

\footnotetext{
${ }^{18} \mathrm{Na}$ "Nota Explicativa" que abre o primeiro volume de $A$ integração do negro na sociedade de classes, Fernandes diz que a análise do negro em São Paulo não apenas poderia ser generalizada para o conjunto das populações "rústicas" recém-imigradas, mas poderia ser vista, "em sentido literal", como "um estudo de como o Povo emerge na história” (Fernandes, 2008b, p. 21). Conforme esclarece Gabriel Cohn, neste livro "o negro apresenta-se como a expressão mais extrema e por isso mesmo mais nítida do personagem histórico do qual não se fala explicitamente, mas que atravessa a análise de ponta a ponta: o povo, na sua forma específica na sociedade brasileira" (Cohn, 2002, p. 389).
} 
nandes e Germani chamaram a atenção para um profundo descompasso na ação do imigrante: se, por um lado, ele foi crucial para a expansão e diferenciação de um setor econômico "moderno", por outro, seu impacto na democratização do sistema político teria sido muito pequeno, permitindo a recomposição das elites tradicionais virtualmente ameaçadas por sua ascensão social.

Em A integração do negro na sociedade de classes, embora esta questão não informe o foco da pesquisa, há algumas indicações bastante precisas a respeito das razões pelas quais os grupos de imigrantes não teriam conseguido abrir o sistema de dominação conformado pelas antigas elites senhoriais. Pela própria posição ocupada na sociedade de classes, diz Fernandes, os imigrantes e seus descendentes se situavam como "um dos polos humanos do desenvolvimento da ordem social competitiva", parecendo-lhe "óbvio que daí poderia ter nascido uma oposição ferrenha à domina204 ção das antigas elites" (Fernandes, 2008b, p. 322). Contudo, em vez de um choque antagônico, teria ocorrido "uma sorte de acomodação mecânica de interesses paralelos". Para o autor:

As camadas dominantes, vindas do passado senhorial e escravista, conservaram-se à testa do poder organizado política, econômica e socialmente. As demais categorias sociais se concentraram no afã de "fazer a fortuna": ou no sentido europeu de "fazer a América"; ou no sentido brasileiro de adquirir o estalão de "gente de prol". O importante é que decorreram quase três gerações antes que entrassem na arena como concorrentes e, até, como opositores daquelas elites. Nesse ínterim, a acomodação aludida proporcionou uma especialização tácita. O poder ficava entre as atribuições indisputadas dos seus executores tradicionais [...]. Os demais "faziam a fortuna”. Para muitos imigrantes, a ilusão do retorno 
ao país de origem contava mais que qualquer motivação suplementar de prestígio ou considerações sociais; para os elementos nacionais, os mecanismos tradicionais de organização do poder enredavam a todos nas malhas do patrimonialismo e da lealdade para com seus interesses (Fernandes, 2008b, p. 323).

No trecho acima, vemos que Fernandes enxerga um relativo atraso na fermentação propriamente política dos imigrantes e seus descendentes (assim como dos brancos nacionais de camadas intermediárias). Isto seria devido não apenas à atuação dos círculos dirigentes, que, como reconhece o autor, tiraram proveito destas circunstâncias e "souberam aproveitá-las com notável egoísmo, para garantir a supremacia de seus interesses e de suas preferências ideológicas". Mas também porque "as camadas 'baixas' e 'intersticiais' da comunidade se envolviam muito mal, quase sempre tangencial ou superficialmente, em assuntos que não possuíssem significação imediata para elas”. Deste modo,

as velhas elites contaram com um tempo de quase três gerações de domínio absoluto, ao sabor do antigo regime, e só então começaram a sofrer os efeitos diretos ou indiretos da presença de outros interesses organizados na luta pelo poder.

Esta situação histórica, algo desconcertante, permitiria ao autor esclarecer

por que a substituição populacional [isto é, a imigração] foi tão importante para a diferenciação da ordem socioeconômica, refletindo-se quase nada nas estruturas políticas e no clima moral da sociedade inclusiva (Fernandes, 2008b, p. 324). 
Neste ponto, reveste-se de interesse a comparação com os argumentos de Germani sobre a escassa participação política dos imigrantes. Não obstante a enorme gravitação destes nos setores mais dinâmicos da economia argentina, assim como as novas possibilidades de participação política institucionalizada a partir de 1916, quando, aproveitando-se da reforma política, sobe ao poder um partido representante das classes médias, a Unión Cívica Radical (UCR, também conhecida como "radicalismo"), o peso político efetivo destes setores teria sido bastante diminuído em virtude da própria condição de "estrangeiro" (o que lhes retirava os direitos políticos). É claro que Germani não deixa de apontar para a importância da ação dos imigrantes nos "grandes movimentos de protesto das primeiras décadas do século". No entanto, ressalta que "é muito provável que os efeitos políticos da aparição dos estratos médios se vissem consideravelmente retardados 206 por sua formação principalmente estrangeira”, o mesmo acontecendo com as classes populares: "o fracasso na formação de um partido capaz de representá-la politicamente obedeceu muito provavelmente a razões semelhantes" (Germani, 1965, p. 221). O autor ainda calcula que em termos eleitorais isto significava que "entre $50 \%$ e $70 \%$ dos habitantes se encontrava à margem de seu exercício legal” (1965, p. 220), tornando o país "eleitoral” bastante distinto do país "real". Em sua hipótese, o fato de que justamente os setores mais "modernizados" tivessem limitado ou anulado o seu acesso aos canais políticos teria feito do "radicalismo", um ator histórico pouco comprometido com as transformações estruturais requeridas na Argentina, o protagonista deste período:

O radicalismo, que governou o país durante catorze anos - até 1930 -, deveria expressar, portanto, todos os novos estratos que surgiram em virtude das mudanças 
na estrutura social, da passagem do padrão tradicional ao "moderno", mas não se pode dizer que cumpriu a sua função. Com efeito, de modo algum utilizou o poder para levar a cabo as transformações na estrutura social que teriam assegurado uma base mais segura para o funcionamento das instituições democráticas e que tenderiam a assegurar a integração de todos os [novos] estratos na medida em que fossem emergindo (Germani, 1965, p. 222).

Fazendo um balanço do que representou este período da história argentina para o processo posterior de incorporação política dos migrantes rurais, Germani chama a atenção para sua herança problemática. Durante as três primeiras décadas do século XX, justamente aquelas nas quais mais se sentiu o impacto da presença do imigrante de ultramar, seria significativa, para além da ausência de reformas estruturais, a não conformação de um forte partido de esquerda e de orientação democrática que fosse capaz de "absorver", através de canais políticos "legítimos", a grande massa que se instalaria na Grande Buenos Aires a partir de meados da década de 1930. Esta seria, para Germani, uma das divergências mais significativas em relação à experiência europeia: na Argentina, afirma,

nem a velha organização sindical, nem os partidos de esquerda ideológica puderam absorvê-los, tal como, por exemplo, ocorre na Itália, com as grandes migrações sul-norte cujas características sociais são tão parecidas (Germani, 1963a, p. 363).

Dito de outro modo, nos países "avançados" teria existido uma sequência histórica capaz de sincronizar minimamente a expansão da participação política com a expansão dos mecanismos institucionais, ou seja, "quando a população 
não incluída se torna ativa”, caso dos migrantes rurais, "existem os mecanismos capazes de canalizar a participação sem transtornos catastróficos para o sistema (ainda que obviamente não sem conflitos mais ou menos agudos)" (Germani, 1963b, p. 421). Já no contexto platino, em virtude da ausência de mecanismos democráticos que pudessem representar as camadas populares "recém-mobilizadas", os migrantes internos encontrariam no "peronismo" o único canal político capaz de expressar suas demandas - com todas as consequências deste fato para a posterior sorte da democracia representativa no país. Neste sentido, a adesão dos "migrantes rurais" ao governo de Perón não se explicaria somente, para Germani, pelos traços culturais "tradicionais" dos primeiros ou pelo tipo "carismático" de liderança exercido pelo segundo, mas também por uma sequência histórica específica na qual entra de maneira decisiva o fracasso dos imigrantes de ultramar na criação de um canal 208 político democrático.

Fernandes, por sua vez, não chegaria a esboçar este tipo de "sociologia política", talvez até porque, no contexto paulista, a relação entre os elementos imigrantes e o "meio negro" e as identidades disponíveis no mundo político não apresentassem a mesma "transparência" na Argentina, a própria emergência do "peronismo", em certo sentido, fez com que a identidade dos migrantes do interior se constituísse de maneira "politizada" e "partidarizada". Em A integração do negro na sociedade de classes, especialmente no segundo volume, a reconstrução histórica da atuação política dos movimentos sociais no "meio negro" feita por Fernandes não passaria, senão muito indiretamente, por suas vinculações com as lideranças partidárias da cidade. O foco argumentativo de Fernandes se concentrou especialmente no impacto destes movimentos no plano da "socialização". Este tipo de abordagem procurou isolar o componente que, no entender do autor, seria 
fundamental destes movimentos: sua contribuição na conformação de "personalidades democráticas", quer dizer, intelectual e moralmente ajustadas à nova ordem social ${ }^{19}$. Mas justamente daí emergiria um dos dilemas históricos mais profundos da sociedade brasileira: apesar de atuarem "como uma espécie de vanguarda intransigente e puritana do radicalismo liberal, exigindo a plena consolidação da ordem social competitiva" (Fernandes, 2008c, p. 9), os movimentos do "meio negro" estavam confinados aos setores mais frágeis da sociedade, uma vez que não conseguiram envolver a sociedade como um todo, nem mesmo os imigrantes de ultramar. Neste "drama histórico", a sociedade brasileira teria deixado aos negros a "responsabilidade de se fazer justiça com as próprias mãos” (2008c, p. 32), condenando ao malogro as tentativas de democratização da sociedade.

O descompasso entre o protagonismo na expansão econômica e na industrialização de São Paulo e da Grande Buenos Aires e o baixo impacto na democratização política faz do imigrante, tal qual aparece nas pesquisas realizadas por Florestan Fernandes e Gino Germani, uma espécie de personagem-síntese da marcha recalcitrante da moderniza-

\footnotetext{
${ }^{19}$ Podemos, com fins de simples conjectura, sugerir que essa circunscrição ao plano da "socialização" permitiu Fernandes realizar uma verdadeira "rotação de perspectivas" em relação à avaliação do significado político dos movimentos negros em São Paulo, especialmente se tivermos em vista as críticas altamente negativas que circulavam sobre a atuação da Frente Negra Brasileira, como as de Paulo Duarte, um dos patrocinadores da pesquisa de Bastide e Fernandes (ver Bastos, 1988). Este último, ao chamar a atenção para as funções ressocializadoras deste movimento, concentrou o argumento sobre seu aspecto mais especificamente "democrático" - o que talvez ficasse bastante obscurecido se tivesse perseguido de maneira sistemática sua conexão com o mundo político-partidário.
} 
ção nos países latino-americanos. Posteriormente, em fins da década de 1960, e cada qual a seu modo, estas características passariam a informar, em suas formulações teóricas, a própria dinâmica dos sistemas sociais nestes casos de modernização tardia, nos quais o vigor da expansão capitalista poderia - ou, no limite, necessitaria - dissociar-se de uma maior democratização do poder político, diferentemente do ocorrido nos países centrais. As formulações de Fernandes $(1968,2006)$ sobre a dinâmica do "capitalismo dependente", assim como as diferentes análises de Germani (1978) sobre a natureza do autoritarismo nas sociedades modernas, fazem parte deste campo problemático. Neste trabalho, procuramos localizar brevemente, em perspectiva comparada, e sem diluir as diferenças que os separam, como o acúmulo intelectual propiciado pelas pesquisas empíricas das décadas de 1950-60 permitiu - ao lado de outros fatores internos e externos, dentre os quais o pró210 prio fechamento político das sociedades brasileira e argentina - que Fernandes e Germani pudessem realizar estas passagens para a teoria sociológica.

\section{Antonio Brasil Jr.}

é doutorando em sociologia pelo Programa de Pós-graduação da UFRJ e bolsista da Faperj.

\section{Referências bibliográficas}

ARRUDA, M. A. N. 2001. Metrópole e cultura: São Paulo no meio século XX. Bauru: Edusc.

BLANCO, A. 2003. "Política, modernización y desarrollo: una revisión de la recepción de Talcott Parsons en la obra de Gino Germani”. Estudios Sociológicos de El Colegio de México, vol. XXI, no 63.

2006. Razón y modernidad: Gino Germani y la sociología en la Argentina. Buenos Aires: Siglo XXI.

. 2009. "José Luis Romero y Gino Germani: la inmigración masiva y el proyecto de una comprensión histórico-sociológica de la Argentina moderna" (mimeo.). 
.; JACKSON, L. C. 2008. "A sociologia no Brasil e na Argentina: alguns pontos de comparação". Paper apresentado no 32을 Encontro da Anpocs. Caxambu (mimeo.).

BASTOS, E. R. 1987. "A questão racial e a revolução burguesa”. In: D'INCAO, M. A. (org.). O Saber militante: ensaios sobre Florestan Fernandes. Rio de Janeiro: Paz e Terra; São Paulo: Ed. Unesp. . 1988. "Um debate sobre a questão do negro no Brasil". São Paulo em Perspectiva, vol. 2, no 2.

. 1996. "Octavio Ianni: a questão racial e a questão nacional". In: FALEIROS, M. I. L.; CRESPO, R. A. (orgs.). Humanismo e compromisso: ensaios sobre Octavio Ianni. São Paulo: Ed. Unesp.

CARDOSO, F. H.; MOREIRA, R. J.; IANNI, O. 1957. "O estudo sociológico das relações entre negros e brancos no Brasil Meridional”. II Reunião Brasileira de Antropologia. Salvador (mimeo.).

COHN, G. 2002. "A integração do negro na sociedade de classes". In: MOTA, L. D. (org.). Introdução ao Brasil: um banquete nos trópicos. São Paulo: Ed. Senac.

COSTA PINTO, L. A. 1959. "Informe sobre el desarrollo de la investigación acerca de la estratificación y movilidad social en cuatro capitales de América Latina”. FFyL-UBA, Publicación interna no 2.

DE ÍPOLA, E. 1989. "Ruptura y continuidad: claves parciales para un balance de las interpretaciones del peronismo". Desarrollo Económico, vol. 29, no 115 .

DEVOTO, F. 1992. "Del crisol al pluralismo: treinta años de estudios sobre las migraciones europeas a la Argentina”. DTS 118, Centro de Investigaciones Social del Instituto Torcuato Di Tella.

FERNANDES, F. 1949. "Resenha de A aculturação dos alemães no Brasil, de Emilio Willems". Revista do Arquivo Municipal, ano XV, vol. CXXII. 1956. "A aculturação dos sírios e libaneses em São Paulo". Revista Etapas, ano I, no 11.

. 1959. "Projeto N. CBPE-78/59 - DEPS 17/59-A-XI do programa de estudos sobre os processos de industrialização e de urbanização no Brasil e seus efeitos sobre a educação", Rio de Janeiro, CBPE. Disponível no "Fundo Florestan Fernandes" da Biblioteca Comunitária da Universidade Federal de São Carlos (UFSCar). . 1967. "O Brasil e o mundo árabe". Revista Etapas, ano XII, no 131. . 1968. Sociedade de classes e subdesenvolvimento. Rio de Janeiro: Zahar. 2006. A revolução burguesa no Brasil. São Paulo: Globo. 
2007. O negro no mundo dos brancos. São Paulo: Global.

. 2008a. Brancos e negros em São Paulo (c/ Roger Bastide). São Paulo: Global.

2008b. A integração do negro na sociedade de classes (1ำ vol.). São Paulo: Globo.

. 2008c. A integração do negro na sociedade de classes ( $2^{\circ}$ vol.). São Paulo: Globo.

GERMANI, G. 1959. "La asimilación de los inmigrantes en la Argentina y el fenómeno del regreso en la inmigración reciente”. FFyL-UBA, publicación interna ํㅜㄴ. 14 .

. 1962a. Encuestas en la ciudad de Buenos Aires (vol. 1). Buenos Aires: Instituto de Sociología, FFyL-UBA (Colección Datos).

. 1962b. "Investigación sobre los efectos sociales de la urbanización en un área obrera del Gran Buenos Aires”. In: HAUSER, P. $L a$ urbanización en América Latina. Unesco.

. 1963a. "La movilidad social en la Argentina". In: BENDIX, R.; LIPSET, S. La movilidad social en la sociedad industrial. Buenos Aires, Eudeba (apéndice II).

. 1963b. "Los procesos de movilización e integración y el cambio social". Desarrollo Económico, no 3, vol. 3.

1965. "Hacia una democracia de masas". In: DI TELLA et al. Argentina, sociedad de masas. Buenos Aires: Eudeba.

. 1970. "Mass immigration and modernization in Argentina".

In: HOROWITZ, I. L. Masses in Latin America. New York: Oxford University Press.

. 1973. El concepto de marginalidad. Buenos Aires: Nueva Visión.

. 1978. Authoritarianism, fascism and national populism. New Jersey:

Transaction Books.

2006. Gino Germani: la renovación intelectual de la sociología (Alejandro Blanco, comp.). Bernal: Universidad Nacional de Quilmes. GRACIARENA, J.; SAUTU, R. 1961. "La investigación de estratificación y movilidad social en el Gran Buenos Aires”. Boletim do Clapcs, oㅡ 4 .

HALPERÍN DONGHI, T. 1975. "Algunas observaciones sobre Germani, el surgimiento del peronismo y los migrantes internos”. Desarrollo económico, vol. 14, ํㅡㄴ 56.

2007. Proyecto y construcción de una nación. Buenos Aires: Emecé.

MARTINS, J. S. 1998. "Vida e história na sociologia de Florestan Fernandes (reflexões sobre o método da história de vida)". In: Florestan: sociologia e consciência social no Brasil. São Paulo: Edusp. 
MARIOSA, D. 2003. Hibridismo e integração nas obras de Florestan Fernandes. Dissertação de mestrado. Campinas: IFCH/Unicamp.

MAIO, M. C. 1997. A história do Projeto Unesco: estudos raciais e ciências sociais no Brasil. Tese de doutorado. Rio de Janeiro: Iuperj.

MICELI, S. 2007. "Les inventeurs latino-américains de la sociologie 'scientifique' (Florestan Fernandes et Gino Germani)”. In: LASK, T. Rapports ambivalents entre sciences sociales européennes et américaines. Milão: Arcipelago Edizioni.

MOREIRA, R. J. 1953. "A história de vida na pesquisa sociológica”. Sociologia, vol. $15, \mathrm{n}^{\circ} 1$.

NEIBURG, F. 1997. Os intelectuais e a invenção do peronismo. São Paulo: Edusp.

SILVA, M. A. M. 2010. "Relações entre ativistas negros e sociólogos uspianos, anos 1950 e 1960”. Comunicação apresentada no II Seminário de Sociologia e Política/UFPR. Curitiba (mimeo.). 


\section{O IMIGRANTE E SEUS IRMÃOS: AS PESQUISAS EMPÍRICAS DE FLORESTAN FERNANDES E GINO GERMANI}

ANTONIO BRASIL JR.

No trabalho, destaco, em perspectiva comparada, algumas formulações de Florestan Fernandes e de Gino Germani, protagonistas da renovação da sociologia nas universidades de São Paulo e de Buenos Aires, respectivamente. Através de pesquisas empíricas, os dois procuraram investigar em que sentido a modernização afetava diferencialmente os grupos sociais, repondo padrões seculares de desigualdade. Fernandes e Germani viram, ainda, no "imigrante de ultramar", o portador por excelência das mudanças em curso, porquanto teria logrado se inserir, tanto em São Paulo quanto em Buenos Aires, nas posições mais dinâmicas da ordem capitalista em expansão, apesar de seu baixo impacto na democratização do sistema de dominação nos dois contextos.

Palavras-chave: Florestan Fernandes; Gino Germani; Imigrante; Sociologia da modernização.

\section{THE IMMIGRANT AND HIS BROTHERS: THE EMPIRICAL RESEARCHES OF FLORESTAN FERNANDES AND GINO GERMANI}

In the paper, I compare some arguments about the social change developed by Florestan Fernandes and Gino Germani, protagonists of the renewal of sociology at the universities of Sao Paulo and Buenos Aires, respectively. Through empirical research, both sought to investigate how the modernization process differentially affected social groups, restoring durable patterns of inequality. Fernandes and Germani considered, moreover, the "immigrant" the main agent of the social changes underway, due to his successful insertion, in Sao Paulo and Buenos Aires, in 
the most dynamic positions of the capitalist order in expansion, despite his low impact on the democratization of the system of domination in both contexts.

Key-words: Florestan Fernandes; Gino Germani; Immigrant; Sociology of modernization.

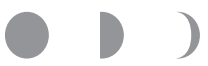

\section{À MODA DE FOUCAULT: UM EXAME DAS ESTRATÉGIAS ARQUEOLÓGICA E GENEALÓGICA DE INVESTIGAÇÃO}

\section{HERMANO ROBERTO THIRY-CHERQUES}

No texto apresento um programa para aplicação da forma de investigar de Michel Foucault às pesquisas em ciências humanas e sociais. A partir da exposição sobre as abordagens arqueológica e genealógica, desenvolvo um roteiro genérico de pesquisa. Discuto, a seguir, os principais instrumentos e conceitos epistemológicos utilizados por Foucault. Concluo com uma apresentação dos paralelismos entre a sua perspectiva e outras modalidades de investigação qualitativa.

Palavras-chave: Método; Foucault; Ciências humanas; Ciências sociais.

\section{LIKE FOUCAULT SENSE: AN EXAM OF THE ARCHEOLOGICAL AND GENEALOGICAL STRATEGIES OF INVESTIGATION}

In the text I present a program for aplication of Michel Foucault's form of investigation for researchs in human and social sciences. Whereof exposition about archeological and genealogical approaches, I develop a generical script of research. I argue, forward, the mainly tools and epistemological concepts used by Foucault. I conclude with a presentation of the parallelisms between his perspective and others types of qualitative investigation.

Keywords: Method; Foucault; Human sciences; Social sciences. 